\title{
Bacterial nanocellulose production and application: a 10-year overview
}

\author{
Angela Faustino Jozala ${ }^{1}$ - Leticia Celia de Lencastre-Novaes ${ }^{2} \cdot$ André Moreni Lopes $^{3}$. \\ Valéria de Carvalho Santos-Ebinuma ${ }^{4}$ Priscila Gava Mazzola ${ }^{2}$ • Adalberto Pessoa-Jr ${ }^{3}$. \\ Denise Grotto $^{1} \cdot$ Marli Gerenutti $^{1} \cdot$ Marco Vinicius Chaud $^{1}$
}

Received: 3 September 2015 /Revised: 7 December 2015 / Accepted: 9 December 2015 / Published online: 8 January 2016

(C) Springer-Verlag Berlin Heidelberg 2016

\begin{abstract}
Production of bacterial nanocellulose (BNC) is becoming increasingly popular owing to its environmentally friendly properties. Based on this benefit of BNC production, researchers have also begun to examine the capacity for cellulose production through microbial hosts. Indeed, several research groups have developed processes for BNC production, and many studies have been published to date, with the goal of developing methods for large-scale production. During BNC bioproduction, the culture medium represents approximately $30 \%$ of the total cost. Therefore, one important and challenging aspect of the fermentation process is identification of a new cost-effective culture medium that can facilitate the production of high yields within short periods of time, thereby improving BNC production and permitting application of $\mathrm{BNC}$ in the biotechnological, medical, pharmaceutical, and food industries. In this review, we addressed different aspects of BNC production, including types of fermentation processes and culture media, with the aim of demonstrating the importance of these parameters.
\end{abstract}

Angela Faustino Jozala

angela.jozala@prof.uniso.br

1 Department of Technological and Environmental Processes, Universidade de Sorocaba - UNISO, Sorocaba, SP, Brazil

2 Faculty of Pharmaceutical Sciences, Universidade de Campinas, UNICAMP, Campinas, Brazil

3 Department of Biochemical and Pharmaceutical Technology, School of Pharmaceutical Sciences, USP, São Paulo, Brazil

4 Department of Bioprocess and Biotechnology, School of Pharmaceutical Sciences, Universidade Estadual Paulista - UNESP, Araraquara, SP, Brazil
Keywords Bacterial nanocellulose $\cdot$ Biopolymers . Biomaterial $\cdot$ Bioprocess $\cdot$ Bioproducts $\cdot$ Fermentation process $\cdot$ Gluconacetobacter xylinus

\section{Introduction}

Ten years of advances in biopolymer research have demonstrated the importance and potential of biopolymers for a variety of applications, particularly for biopolymers produced by microorganisms, including bacterial nanocellulose (BNC). Many types of BNCs have been developed for various applications, including tissue regeneration, drug delivery systems, vascular grafts, and scaffolds for tissue engineering in vitro and in vivo (Czaja et al. 2007; de Azeredo 2013; Almeida et al. 2014; Oliveira Barud et al. 2015; Martínez-Sanz et al. 2016).

Depending on the purpose of the application, BNC can provide improved mechanical qualities to the biomaterial owing to its biocompatibility, biofunctionality, lack of toxicity, and ease of sterilization (Klemm et al. 2011). For this reason, there are currently several methodologies for large-scale production of BNC. Researchers have focused on improving the efficiency of the production process, resulting in satisfactory yields that are compatible with the demand for this type of cellulose (Lin et al. 2014; Zhang et al. 2014; Cakar et al. 2014; Li et al. 2015).

The culture medium is the most important factor for the total cost of production of BNC. Therefore, one important aspect in $\mathrm{BNC}$ production is to identify a low-cost culture medium that can improve the yield of BNC and be used as an economically viable solution for application in a range of fields (Cakar et al. 2014; Padmanaban et al. 2015).

Therefore, the aim of this review is to discuss advancements in BNC production within the last 10 years. To this 
end, we will describe the types of processes and culture media used for BNC production. We also discuss the potential applications of BNC.

\section{Cellulose}

Cellulose is the most common natural polymer worldwide. According to a worldwide estimate, $10^{14} \mathrm{t}$ of cellulose pulp are produced each year, emphasizing the economic importance of this polymer (Donini et al. 2010; Lin et al. 2014). Due to the presence of components other than cellulose, different chemical treatments employing highly polluting chemical products, such as chlorine gas, caustic soda, carbon disulfide, carbon monoxide, and carbon dioxide, are often needed prior to use in order to obtain pure cellulose (Basta and El-Saied 2009; Klemm et al. 2011).

Donini et al. (2010) compared the productivity of cellulose from plants and microorganisms in order to determine the advantages of producing cellulose from microorganisms. In their analysis, they compared the production of cellulose from 1 ha of eucalyptus with a mean annual increment (MAI) of $50 \mathrm{~m}^{3}$, providing a basic density of $500 \mathrm{~kg} / \mathrm{m}^{3}$; this generated an MAI of $25 \mathrm{t} / \mathrm{ha} /$ year. With 7 years from planting to cultivation, yielding about $45 \%$ cellulose contents, this process would yield about $80 \mathrm{t}$ of cellulose/ha after 7 years of cultivation. The authors found that the same production could be achieved with bacteria to a hypothetical yield of $15 \mathrm{~g} / \mathrm{L}$ in $50 \mathrm{~h}$ of culture (average of $0.3 \mathrm{~g} / \mathrm{h}$ ) in a bioreactor of $500 \mathrm{~m}^{3}$ in approximately 22 days. This more efficient production method also yielded pure and ecologically sustainable BNC as the product.

Unlike plant cellulose, $\mathrm{BNC}$ is produced in the pure form, devoid of lignin, hemicellulose, pectin, or any other compound present in the plant pulp and does not contain components of animal origin. In addition, it has superior mechanical properties compared with plant cellulose (Fu et al. 2013).

The anhydroglucose units and various bacterial cellulose fibrils interact closely with each other to form a crystalline structure through internal and external hydrogen bonds, resulting in the compaction of fibers that are completely insoluble in water but that can be hydrated (Lynd et al. 2002; Conley et al. 2016) The thin nanofibers have a diameter of 20-100 nm, with a large surface area per unit; this feature, combined with the hydrophilic nature of BNC, results in high water absorption capacity, better adherence, and increased moisture content (Fu et al. 2013; Numata et al. 2015b). These properties, combined with the distinct physical and mechanical properties of the molecule, including its insolubility, rapid biodegradability, tensile strength, elasticity, durability, and nontoxic and nonallergenic features, make BNC ideal for the production of several products with high added value, such as artificial skin used as a temporary substitute in the treatment of burns and other dermal injuries (Thompson and Hamilton 2001; Rehim et al. 2014; Cakar et al. 2014).

BNC is a highly crystalline linear polymer of glucose synthesized mainly by the bacterium Gluconacetobacter xylinus (formerly named Acetobacter xylinus). Although BNC production has been studied primarily in G. xylinus, other microorganisms also exhibit the ability to synthesize this biopolymer, such as other species of Gluconacetobacter, Agrobacterium tumefaciens, Rhizobium spp., and Grampositive Sarcina ventriculli (Tanskul et al. 2013; Mohammadkazemi et al. 2015).

G. xylinus is the primary microbial producer of BNC and has become a model system for the study of the biosynthetic mechanisms of BNC in bacteria (Keshk 2014). For cellulose production, G. xylinus builds a nanofibrilar film with a denser lateral surface and a gelatinous layer on the opposite side (Kurosumi et al. 2009; Cai and Kim 2009). The biochemical process of cellulose synthesis by $G$. xylinus consists of three main steps: (i) polymerization of glucose residues in $\beta-1-4$ glucan, (ii) extracellular secretion of linear chains, and (iii) organization and crystallization of glucan chains through hydrogen bonds and van der Waals forces arrayed in a hierarchy into strips. Thus, microfibril cellulose is produced (Donini et al. 2010; Klemm et al. 2011).

Despite the above studies, the metabolic pathways through which microorganisms regulate BNC production remain unclear. Moreover, it is still necessary to identify new microorganisms that can produce this biopolymer.

\section{Biotechnology-based production of BNC}

The production of environmentally friendly products is becoming increasingly important; in this context, the production of nanocellulose through microbial pathways is advantageous. Indeed, BNC production using microorganisms is industrially important because such microorganisms exhibit rapid growth, allowing for high yields and year-round availability of product (Santos-Ebinuma et al. 2013).

There are two main methods for producing BNC using microorganisms: static culture, which results in the accumulation of a thick, leather-like white BC pellicle at the air-liquid interface (Kuo et al. 2015), and stirred culture, in which cellulose is synthesized in a dispersed manner in the culture medium, forming irregular pellets or suspended fibers (Krystynowicz et al. 2002; Czaja et al. 2004). The choice between these two types of production (i.e., static or stirred culture) depends on the final application of BNC since the morphological, physical, and mechanical properties of the 
formed polymer vary according to the method of cultivation. For example, cellulose produced by stirred culture has low mechanical strength compared with that produced by static culture. Moreover, stirred culture results in lower yields than static cultures and a higher probability of mutations in the microorganism, which may affect the production if BNC. On the other hand, static culture requires a larger cultivation area and a longer culture time (Chawla et al. 2009; Keshk 2014; Cakar et al. 2014; Lee et al. 2014; Jeon et al. 2014; Tyagi and Suresh 2015).

Some considerations must be taken into account when determining the conditions necessary to produce BNC. The costbenefit from the culture medium in terms of yield of BNC is an important factor, and therefore, the composition and volume of the medium should be considered. The composition of the culture medium can directly affect the profitability of the biotechnological process and is therefore critical for the production of any bioproduct, including BNC (Ruka et al. 2012; Lee et al. 2014; Mohammadkazemi et al. 2015).

The fermentation medium must contain, at minimum, a carbon source, a nitrogen source, and other macro- and micronutrients required for the growth of the microorganism, such as phosphorus, sulfur, potassium, and magnesium salts (Krystynowicz et al. 2002; Chawla et al. 2009; Mohammadkazemi et al. 2015).

The synthesis of cellulose is susceptible to chemical agents and the physical influence of the compounds present during its production. Thus, regardless of the method of production, factors such as yield, morphology, structure, and physical properties may be affected by the culture medium used (Jung et al. 2010; Ruka et al. 2012; Mohammadkazemi et al. 2015).

The culture medium typically used for the production of $\mathrm{BNC}$, regardless of the use of static or stirring culture, was first described in 1954 by Hestrin and Schramm (HS) (Schramm and Hestrin 1954). This medium is composed of $2 \%$ glucose (the major carbon source), $0.5 \%$ peptone, $0.5 \%$ yeast extract, $0.27 \%$ of anhydrous disodium phosphate, and $0.15 \%$ citric acid monohydrate. However, HS medium can increase the final production cost of the biopolymer and is considered unfeasible for commercial production of BNC due to its high cost (Tyagi and Suresh 2015; Huang et al. 2016). For this reason, various studies have been performed over the last 10 years to improve BNC production based on several fermentation parameters, such as $\mathrm{pH}$ control, and alternative carbon sources, including sugar cane, molasses, sucrose, and rotten fruit, as well as culture in a static and agitated environment (Table 1).

Gluconacetobacter can use several carbon sources to synthesize BNC. Glucose is the most often used because it is both an energy source and the ideal precursor for obtaining cellulose during the biosynthesis process. However, BNC yield may be low because of the presence of glucose dehydrogenase, which converts glucose into gluconic acid, thereby decreasing the $\mathrm{pH}$ of the culture and potentially affecting BNC biosynthesis, is present in the cell membrane of G. xylinus (Kuo et al. 2015)).

Beginning in 2006, Keshk and Sameshima studied the use of HS culture medium alone and in the presence of $1 \%$ lignosulfonate (HSL) in six strains of G. xylinus ( $G$. xylinus IFO $13693,13,772,13,773,14,815$, and 15,237$)$ in static culture to produce BNC. The strains G. xylinus IFO 13693 and 13,773 exhibited the highest BNC production in HSL (around $16.32 \mathrm{~g} / \mathrm{L}$ for both strains), which was higher than that obtained in HS (close to $7.92 \mathrm{~g} / \mathrm{L}$ ).

According to the authors, the presence of lignosulfonate promotes an increase in BNC production due to the inhibition of gluconic acid formation in the presence of antioxidant polyphenolic compounds in the lignosulfonate. In experiments performed with lignosulfonate, the $\mathrm{pH}$ was closer to 4.0 for all strains, whereas under other conditions, the final $\mathrm{pH}$ was around 3.0, which could be explained by gluconic acid production. Furthermore, FT-IR results showed that the BNC produced in the presence of lignosulfonate displayed a higher crystallinity index and $\mathrm{I}_{\alpha}$-rich cellulose.

In 2009, Mikkelsen and coworkers studied the production of BNC by G. xylinus ATCC 53524 under static culture conditions using modified HS medium by replacing glucose with different carbon sources, i.e., mannitol, glycerol, fructose, sucrose, and galactose. Sucrose and glycerol showed the highest cellulose yields of 3.83 and $3.75 \mathrm{~g} / \mathrm{L}$, respectively, after $96 \mathrm{~h}$ of fermentation, whereas mannitol, fructose, and glucose (in the original HS medium) resulted in yields below $2.5 \mathrm{~g} / \mathrm{L}$.

Cross-polarization/magic angle spinning (CP/MAS) ${ }^{13} \mathrm{C}$ NMR spectroscopy showed that irrespective of the carbon source used, the cellulose produced by was pure and crystalline. These findings demonstrate the ability of G. xylinus to metabolize different sources of carbon to produce BNC. According to the authors, although the rate and extent of cellulose production was characteristic for the carbon source, the microscopic and molecular organization of cellulose produced was highly conserved, suggesting that differences in productivity due to the carbon source were due to substrate limitations, rather than changes in polymerization.

In the same year, Kurosumi and collaborators reported the production of cellulose by Acetobacter xylinum NBRC 13693 using juices (orange, apple, pineapple, Japanese pear, and grape) as culture media. The authors evaluated different conditions for these juices: fruit juice adjusted $\mathrm{pH} 6$ with a nitrogen source of HS medium (medium I), fruit juice adjusted to pH 6 (medium II), and sugar reagents (glucose, fructose, and sucrose) with a nitrogen source in HS medium (medium III). The content and type of sugar present in each fruit juice varied, and the authors suggested that appreciable amounts of the bacterial cellulose could be produced from fruit juices containing an abundance of sucrose and fructose. The authors found a 
Table 1 Conditions, yields, production methods and microorganisms used to produce bacterial nanocellulose described in the literature starting in 2006

\begin{tabular}{|c|c|c|c|c|}
\hline Carbon source & $\begin{array}{l}\text { BNC Yield } \\
(\mathrm{g} / \mathrm{L})\end{array}$ & Production method & Microorganism & Reference \\
\hline HS in the presence of $1 \%$ lignosulfonate & 16.32 & Static culture at $28^{\circ} \mathrm{C}$ for $168 \mathrm{~h}$ & G. xylinus IFO 13693 & $\begin{array}{l}\text { (Keshk and Sameshima } \\
\text { 2006) }\end{array}$ \\
\hline Sucrose & 3.83 & Static culture at $30^{\circ} \mathrm{C}$ for $96 \mathrm{~h}$ & G. xylinus ATCC 53524 & (Mikkelsen et al. 2009) \\
\hline $\begin{array}{l}\text { Orange juice containing nitrogen sources of } \\
\text { HS }\end{array}$ & 5.90 & Static culture at $30^{\circ} \mathrm{C}$ for $96 \mathrm{~h}$ & $\begin{array}{l}\text { Acetobacter xylinum } \\
\quad \text { NBRC } 13693\end{array}$ & (Kurosumi et al. 2009) \\
\hline Glucose in the presence of MCP-1 & 1.20 & $\begin{array}{l}\text { Stirred culture at } 30^{\circ} \mathrm{C} \text { and } \\
125 \mathrm{rpm} \text { for } 288 \mathrm{~h}\end{array}$ & $\begin{array}{l}\text { Acetobacter xylinum } \\
\text { JCM } 9730\end{array}$ & $\begin{array}{l}\text { (Hu and Catchmark } \\
\text { 2010) }\end{array}$ \\
\hline $\begin{array}{l}\text { Molasses and corn steep liquor in the } \\
\text { presence of acetic acid }\end{array}$ & 3.12 & $\begin{array}{l}\text { Stirred culture at } 30{ }^{\circ} \mathrm{C} \text { and } \\
200 \mathrm{rpm} \text { for } 168 \mathrm{~h}\end{array}$ & Acetobacter sp. V6 & (Jung et al. 2010)) \\
\hline Glucose & 2.70 & Static culture at $30^{\circ} \mathrm{C}$ for $96 \mathrm{~h}$ & G. sacchari & (Trovatti et al. 2011)) \\
\hline $\begin{array}{l}\text { Glucose (HS broth supplemented with n- } \\
\text { butanol) }\end{array}$ & 1.33 & Static culture at $30^{\circ} \mathrm{C}$ for $144 \mathrm{~h}$ & A. xylinum 186 & (Lu et al. 2011) \\
\hline HS broth supplemented with thin stillage & 10.22 & Static culture at $30{ }^{\circ} \mathrm{C}$ for $168 \mathrm{~h}$ & G. xylinus (BCRC 12334) & (Wu and Liu 2012) \\
\hline Industrial residues from olive oil production & 1.28 & - & G. sacchari & $\begin{array}{l}\text { Gomes et al. (Gomes et } \\
\text { al. 2013) }\end{array}$ \\
\hline Molasses & 1.64 & $\begin{array}{l}\text { Static semicontinuous process for } \\
168 \mathrm{~h}\end{array}$ & G. xylinus (FC01) & $\begin{array}{l}\text { Çakar et al. (Cakar et al. } \\
\text { 2014) }\end{array}$ \\
\hline Waste beer yeast treated with ultrasonication & 7.02 & $\begin{array}{l}\text { Stirred culture at } 30^{\circ} \mathrm{C} \text { and } \\
150 \mathrm{rpm}\end{array}$ & $\begin{array}{l}\text { G. hansenii CGMCC } \\
3917\end{array}$ & $\begin{array}{l}\text { Lin et al. (Lin et al. } \\
\text { 2014) }\end{array}$ \\
\hline Rotten fruit culture & 60 & Static culture at $30{ }^{\circ} \mathrm{C}$ and $96 \mathrm{~h}$ & G. xylinus ATCC 53582 & (Jozala et al. 2015)) \\
\hline Wood hot water extract & 0.15 & Static culture at $28{ }^{\circ} \mathrm{C}$ for $672 \mathrm{~h}$ & $\begin{array}{l}\text { Acetobacter xylinum } \\
\text { 23,769 }\end{array}$ & $\begin{array}{l}\text { (Erbas Kiziltas et al. } \\
\text { 2015b) }\end{array}$ \\
\hline Waste water of candied jujube hydrolysate & 2.25 & Static culture at $30{ }^{\circ} \mathrm{C}$ for $144 \mathrm{~h}$ & G. xylinus CGMCC 2955 & (Li et al. 2015) \\
\hline Citrus Juice and sucrose & - & Static culture at $30^{\circ} \mathrm{C}$ & G. sp.gel_SEA623-2 & (Kim et al. 2015) \\
\hline Lipid fermentation wastewater & 0.66 & Static culture at $28^{\circ} \mathrm{C}$ for 5 days & G. xylinus $\mathrm{CH} 001$ & (Huang et al. 2016) \\
\hline
\end{tabular}

$H S$ Hestrin-Schramm culture medium, $M C P-1$ methylcyclopropane-1

higher cellulose yield $(5.9 \mathrm{~g} / \mathrm{L})$ in culture medium containing orange juice supplemented with a nitrogen source after $96 \mathrm{~h}$ of bioprocessing. The BNC produced from this experiment was not characterized; therefore, it is not possible to determine whether the sugars present in different fruit juices generated $\mathrm{BNC}$ molecules with differential characteristics.

Jung et al. (2010) employed molasses and corn steep liquor to reduce the cost of the culture media in stirred culture. The authors found that the final $\mathrm{pH}$ in the presence of molasses was around 5.0 under several conditions, resulting in reduced production of gluconic acid because molasses components have lower amounts of glucose. The authors also evaluated whether the presence of organic acids (i.e., acetic acid, citric acid, lactic acid, pyruvic acid, and malic acid) would promote an increase in BNC biosynthesis. As result, the presence of acetic acid generated the highest yield $(3.12 \mathrm{~g} / \mathrm{L})$. Moreover, FT-IR spectra of the BNC produced from the molasses and complex media showed similarities, indicating that the microorganisms could metabolize different carbon sources, producing $\mathrm{BNC}$ with the same characteristics.

Trovatti et al. (2011) first reported the production of BNC by Gluconacetobacter sacchari, isolated from Kombucha tea.
The strain harvested in HS medium containing glucose, sucrose, fructose, mannitol, or glycerol as the carbon source yielded the highest cellulose production $(2.7 \mathrm{~g} / \mathrm{L}$ in $96 \mathrm{~h})$ when glucose was the carbon source. This value was consistent with that obtained from other cellulose-producing strains, and the structure of the cellulosic matrix obtained was identical to that produced by other bacteria.

Lu et al. (2011) studied the effects of six different alcohols (methanol, ethylene glycol, $n$-propanol, glycerol, $n$-butanol, and mannitol) added in the HS medium on cellulose production by strain A. xylinum 186 in static culture at $30^{\circ} \mathrm{C}$ for 6 days. Interestingly, the addition of $1 \%$ methanol produced a yield of $1.04 \mathrm{~g} / \mathrm{L}$, whereas the addition of $0.5 \%$ ethylene glycol, $n$-propanol, or $n$-butanol produced yields of 1.06, 0.96 , and $1.33 \mathrm{~g} / \mathrm{L} \mathrm{BNC}$, respectively. The use of $3 \%$ glycerol yielded $1.08 \mathrm{~g} / \mathrm{L} \mathrm{BNC}$, and the addition of $4 \%$ mannitol yielded $1.25 \mathrm{~g} / \mathrm{L}$ BNC. Therefore, alcohols could be classified (in order from highest to lowest) based on BNC yield, as follows: $n$-butanol $>$ mannitol $>$ glycerol $>$ ethylene glycol $>$ methanol $>n$-propanol.

Wu and Liu (2012) studied HS broth supplemented with thin stillage (TS), which is the liquid portion of distillery 
stillage from the fermentation of grain-based feedstock rich in organic acids and amino acids. The authors observed that complete replacement of glucose with TS enhanced the production of BNC, achieving a BNC yield of $10.22 \mathrm{~g} / \mathrm{L}$ under conditions in which the TS was $100 \%$ after 7 days of cultivation. According to the authors because TS is rich in organic acids, it could support the growth of G. xylinus, and the glucose in HS medium could be employed for BC biosynthesis. Therefore, the production of gluconic acid was low, promoting the highest production of BNC.

Gomes et al. (2013) studied the production of BNC by $G$. sacchari using industrial residues from olive oil (DOR) as nutrients and a carbon source. BNC production without the addition of any nutrients was around $0.80 \mathrm{~g} / \mathrm{L}$ after $96 \mathrm{~h}$ of incubation, whereas conventional HS medium produced around $2.5 \mathrm{~g} / \mathrm{L}$ BNC. Supplementation with olive oil residues containing nitrogen and phosphate sources $\left[\left(\mathrm{NH}_{4}\right)_{2} \mathrm{SO}_{4}\right.$ and $\mathrm{KH}_{2} \mathrm{PO}_{4}$, respectively] resulted in a 2-fold increase in BNC production compared with unsupplemented medium. The BNC produced employing DOR as carbon source exhibited a typical homogeneous three-dimensional network of nanoand microfibrils of cellulose, as previously reported for BNC.

Çakar et al. (2014) evaluated the production of cellulose using a static semicontinuous process in molasses medium. The authors achieved a maximum cellulose yield $(1.64 \mathrm{~g} / \mathrm{L})$ when using a molasses ratio of $1: 2$ for 7 days. The use of molasses as a carbon source produced BNC with structure that changed from thin fibrils to a web-like pattern according to the incubation period. However, in general, the BNC produced exhibited a dense fibril structure.

Lin et al. (2014) used waste beer yeast (WBY) to improve BNC production by Gluconacetobacter hansenii CGMCC 3917. WBY hydrolysates, treated with ultrasonication, exhibited a high cellulose yield (7.02 g/L), almost 6-fold higher than that from untreated WBY $(1.21 \mathrm{~g} / \mathrm{L})$. This result can be explained by the fact that the uncentrifuged samples after pretreatment had a high sugar concentration (and showed the highest sugar yields), which could inhibit BNC production and reduce the supply of oxygen by the liquid medium. The properties and microstructure of BNC produced by WBY hydrolysates were as good as those obtained from the conventionally used chemical media.

Jozala et al. (2015) evaluated HS broth, milk whey, rotten fruit (plums, green grapes, pineapples, and apples) and combined milk whey/rotten fruit at different proportions as alternative sources to produce BNC by G. xylinus ATCC 53582 at $30{ }^{\circ} \mathrm{C}$ in a static culture for $0,24,48,72$, or $96 \mathrm{~h}$. The highest production was observed after $96 \mathrm{~h}$ of bioprocessing using rotten fruit as main carbon source. The production achieved with this alternative medium was higher than obtained with HS medium (standard medium) and those reported in several previous reports. Figure 1 shows BNC produced by culture medium containing rotten fruits.

Li et al. (2015) studied the use of wastewater of candied jujube (WWCJ) for G. xylinus CGMCC No. 2955 under static culture to obtain BNC. According to the authors, WWCJ contained mainly glucose, glucan, and very low levels of other carbohydrates, providing an interesting carbon source with which to obtain BNC. WWCJ was used in three different conditions, namely WWCJ media containing ammonium citrate, sodium dihydrogen phosphate, and calcium carbonate, WWCJ without ammonium citrate, and WWCJ hydrolysate at $80{ }^{\circ} \mathrm{C}$. The bioprocess took 6 days and promoted the production of BNC in all conditions analyzed. However, the WWCJ without ammonium citrate media generated the lowest BNC yield $(0.25 \mathrm{~g} / \mathrm{L})$, indicating that ammonium citrate could be a key factor for BNC production. With WWCJ and the hydrolysate, the BNC yields were 1.50 and $2.25 \mathrm{~g} / \mathrm{L}$, respectively.

Kim et al. (2015) isolated a new BCN-producing strain identified as G. sp. gel_SEA623-2 from citrus fruit juice. The authors evaluated BNC production through five fruit juices, including orange, grape, apple, and pear juices, at several $\mathrm{pH}$ values $(2.0,2.5,3.0,3.5,4.0$, and 5.0$)$, temperatures $\left(20,30,35\right.$, and $\left.40^{\circ} \mathrm{C}\right)$, and brix values $(5,10,20$, and 30$)$ during static culture. Among the fruit juice sources examined,
Fig. 1 Bacterial Nanocellulose produced by culture medium composed by rotten fruits. $A$ After tretatment with $\mathrm{NaOH} ; B 1, B 2$ size and thikness, $C$ transparency. (source: personal files)

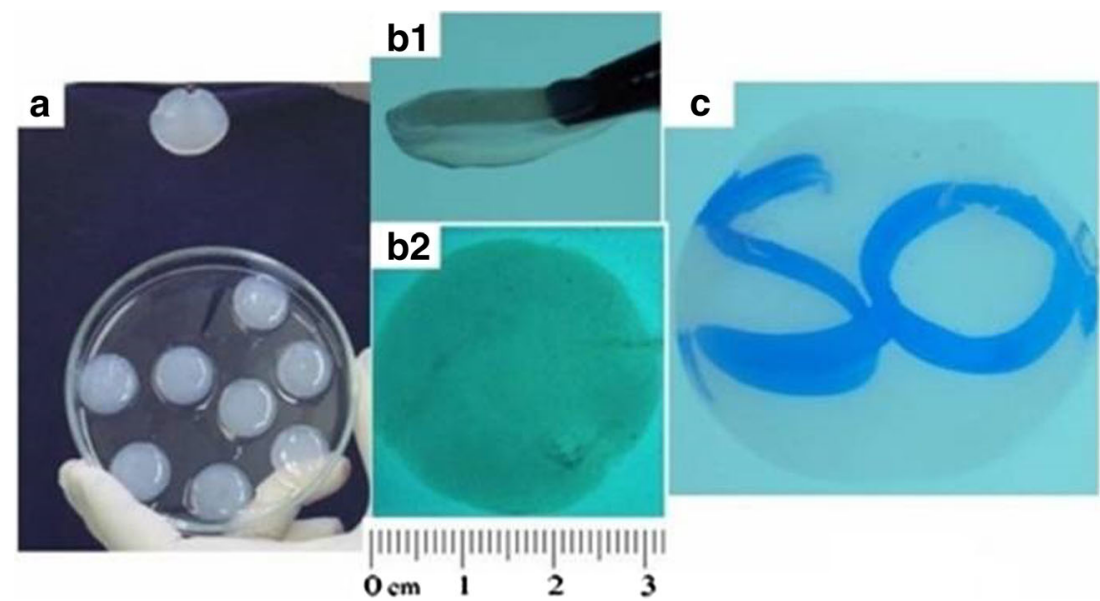


unshu juice was the most favorable for BNC production by $G$. sp. gel SEA623-2, showing that this bacteria had a high productive capacity in a citrus processing medium. The optimum $\mathrm{pH}$ and temperature for $\mathrm{BNC}$ production were 3.5 and $30^{\circ} \mathrm{C}$, respectively.

Erbas Kiziltas et al. (2015b)evaluated wood hot water extract (HWE), a residual material originating from pulp mills and lignocellulosic biorefineries for the production of BNC using A. xylinum 23,769 . This source had mainly monomeric sugars, organic acids, and organics compounds. The cultivation was performed under static culture by varying the $\mathrm{pH}$ range from 5 to 8 and temperature range from 26 to $30{ }^{\circ} \mathrm{C}$ for $\mathrm{BC}$ production from A. xylinum 23,769 in HWE. Although an acidic $\mathrm{pH}$ generally promotes high $\mathrm{BNC}$ production, the authors found that the maximum production of $\mathrm{BNC}(0.15 \mathrm{~g} /$ L) was achieved at a pH of 8 and a temperature of $28^{\circ} \mathrm{C}$. In addition, the results achieved by the authors showed that the fractured surface morphology of the BNC pellicles from wood HWE exhibited a smaller cellulose fibril diameter compared with the $\mathrm{BC}$ pellicles from the HS medium.

Kuo et al. (2015) evaluated the effects of $100 \mathrm{mM}$ acetate buffered at different $\mathrm{pH}$ on $\mathrm{BNC}$ production by static cultivation of G. xylinus. After 8 days of cultivation, the maximum amount of BNC produced was $2.98 \mathrm{~g} / \mathrm{L}$ when $20 \mathrm{~g} / \mathrm{L}$ glucose was employed in $100 \mathrm{mM}$ acetate-buffered medium at $\mathrm{pH}$ 4.75. In contrast, the BC produced in yeast extractpeptone-dextrose broth (YPD) and HS media was only 0.66 and $1.23 \mathrm{~g} / \mathrm{L}$, respectively. The final $\mathrm{pH}$ of acetate-buffered medium (buffered at $\mathrm{pH} 4.75,5.50$, and 6.00) was close to its initial value. However, the final $\mathrm{pH}$ of YPD and HS media was lower than 3.5. Acetate-buffered medium can maintain a $\mathrm{pH}$ environment suitable for $\mathrm{BC}$ biosynthesis for a longer time as compared with traditional unbuffered HS medium. These results clearly showed the effects of $\mathrm{pH}$ on $\mathrm{BNC}$ production.

Huang and co-authors (2016) were the first to use lipid fermentation wastewater (fermentation broth after separation with yeast biomass) as a substrate for BNC production by $G$. xylinus. The chemical oxygen demand (COD) value of lipid fermentation wastewater was $25.59 \mathrm{mg} / \mathrm{L}$, which could result in low BNC yield. According to the authors, the pretreatment of lipid fermentation wastewater to hydrolyze the extracellular polysaccharides may make the wastewater more biodegradable and could improve BNC production by reducing the production cost of BNC. Moreover, the lipid fermentation wastewater environment had only minor effects on the structure of BNC.

During the last 10 years, several groups have tested alternative carbon sources aiming to increase BNC yields and decrease production costs (Table 1). Carbon sources with low sugar contents have generated interesting results. Although the use of alternative carbon sources can improve BNC production, it is also necessary to control the environmental conditions, such as $\mathrm{pH}$ and temperature. Temperature is a crucial factor that affects the growth of microorganisms, thereby influencing cellulose production.

In addition to temperature and $\mathrm{pH}$, the dissolved oxygen concentration in the culture medium is an important factor that can affect the production of cellulose. In static cultures, the substrate must be transported entirely by diffusion, and because the carbon sources are generally available, the low availability of oxygen can become the limiting factor for cell metabolism and can have a negative effect on cellulose production and quality (Chawla et al. 2009). Ruka and collaborators (2012) found that the production of cellulose increases as the surface area of static medium and medium volume increase; however, this enhanced yield is also associated with increased cost and production time.

During the biosynthesis of BNC, if the culture broth contains different components, such as organic, inorganic, or polymeric materials, these components can be incorporated into the membrane of $\mathrm{BNC}$, promoting the functionalization of BNC. There are two basic synthetic approaches for creating BNC matrix composites: in situ and ex situ. In the in situ method, secondary components can be introduced into the $\mathrm{BNC}$ culture media at the beginning of the BNC synthesis process. For the ex situ method, secondary components can be introduced into the BNC matrix by the solution impregnation method (Erbas Kiziltas et al. 2015a).

The effects of chondroitin sulfate and hyaluronic acid in bacterial cellulose production were studied by Molina de Olyveira et al. (2013). The authors analyzed BNC production using transmission infrared spectroscopy (FTIR), X-ray diffraction (XRD), and scanning electron microscopy (SEM). FTIR analysis showed an interaction between bacterial cellulose nanobiocomposites and calcium phosphate. Thus, the addition of different compounds in the culture medium can direct the formation of bacterial cellulose with specific characteristics.

Kiziltas et al. (2015b) studied the biosynthesis of BNC by A. xylinum 23,769 in the presence of different nanoparticles (cellulose nanofibrils [CNFs], exfoliated graphite nanoplatelets $[\mathrm{xGnPs}]$, and nanoclay $[\mathrm{NC}]$ ) using an in situ approach. All BC-based nanomaterials produced exhibited good dispersion of the NPs within the BC matrix, and the NPs were found embedded among the voids and microfibrils. The thermal stability and residual mass of $\mathrm{BNC}-\mathrm{xGnP}$ and BNC-NC nanomaterials were significantly increased compared with that of pure BNC. CNF incorporation into the $\mathrm{BNC}$ matrix did not change the thermal stability and residual mass of the BNC matrix.

The cultivation method is also an important parameter that should be analyzed in greater detail. Static culture is the most commonly used method; however, many bioreactors contain a stirred tank, conventional airlift, and modified airlift with a rectangular wire-mesh draft tube. The BNC obtained from these types of bioreactors is fibrous or in pellet form 
(Kralisch et al. 2010; Lee et al. 2014; Wu and Li, 2015), and this technology may generate promising results. Therefore, further studies are needed to examine BNC functionalization during its biosynthesis, which may be a key factor to promote the market expansion of this biomaterial.

\section{Applications of BNC}

Based on the properties of BNC, including its high purity, high degree of crystallinity, high density, good shape retention, high water-binding capacity, and higher surface area as compared to native cellulose, BNC may have applications in a variety of contexts, such as the textile industry, nonwoven cloth, paper, food, pharmaceuticals, waste treatment, broadcasting, mining, and refineries (Table 2) (Wu and Liu 2012; Ashjaran et al. 2013; Lin and Dufresne, 2014). These distinctive properties have facilitated the use of BNC in the fabrication of several different products, including tires, headphone membranes, high performance speaker diaphragms, highgrade paper, make-up pads, diet foods, and textiles (Shah et al. 2013).

Fragmented BNC has potential applications in papermaking, allowing the production of flexible/durable paper and paper with high filler content, which is ideal for banknote paper (Chawla et al. 2009; Ashjaran et al. 2013), and its use as a binding agent in papermaking has been investigated (Basta and El-Saied 2009). Mautner et al. (2015) demonstrated that BNC-based nanopaper was suitable for tight ultrafiltration operations, while Li et al. (2015) developed a low-cost and environmentally friendly paperbased energy-storage device using bacterial cellulosepolypyrrole nanofibers in combination with multiwalled carbon.
Chemically pure cellulose can be used in processed foods as a thickening and stabilizing agent or for the promotion of gelling and water binding. Moreover, BNC is a type of dietary fiber and has been classified as a "generally recognized as safe" (GRAS) food, approved for marketing by the US Food and Drug Administration (FDA) in 1992 (Shi et al. 2014). The first use of BNC in the food industry was in "Nata" in the Philippines; Nata is made from a BNC gel and is a traditional dessert in Southeast Asia (Chawla et al. 2009; Shi et al. 2014). There are many types of Nata, including Nata de coco and Nata de pina, and the flavors of these products are controlled by the culture medium source. For example, Nata de coco uses coconut as the source, whereas Nata de Pina uses pineapple as the source (Shi et al. 2014).

Cellulose-producing microorganisms can be grown in culture medium sources, such as fruit syrup, that allow the produced cellulose to acquire the nature flavor and pigment of the fruit. Moreover, BNC can be produced to have a variety of shapes and textures, giving BNC many different applications in foods (Shi et al. 2014).

Owing to its unique nanoscaled 3D network structure, $\mathrm{BNC}$ can serve as a natural scaffold material for the regeneration of a wide variety of tissues (Fu et al. 2013). The most exciting applications of this biomaterial are in the biomedical field, where BNCs have been used as wound dressing materials, artificial skin, vascular grafts, scaffolds for tissue engineering, artificial blood vessels, medical pads, and dental implants (Shah et al. 2013). The many advantages of BNC, including its biocompatibility, conformability, elasticity, transparency, ability to maintain a moist environment in the wound, and ability to absorb exudates during the inflammatory phase, provide great potential for applications in wound healing systems. A thorough review of the most recent developments in
Table 2 Bacterial nanocellulose applications in different areas

\begin{tabular}{|c|c|}
\hline Area & Application \\
\hline Cosmetics & Stabilizer of emulsions like creams, tonics, conditioners, nail polishes. \\
\hline Textile industry & Sports clothing, tents and camping equipment \\
\hline $\begin{array}{l}\text { Mining and } \\
\text { refinery }\end{array}$ & Sponges to collect leaking oil, materials for absorbing toxins. \\
\hline Waste treatment & Recycling of minerals and oils \\
\hline $\begin{array}{l}\text { Sewage } \\
\text { purification }\end{array}$ & Urban sewage purification, ultra filtration water \\
\hline Communications & Diaphragms for microphones and stereo headphones \\
\hline Food industry & Edible cellulose (nata de coco) \\
\hline Paper industry & Artificial replacement of wood, special papers \\
\hline $\begin{array}{l}\text { Medicine/ } \\
\text { biomedical }\end{array}$ & $\begin{array}{l}\text { Temporary artificial skin for burns and ulcers, dental implant components; Antimicrobial } \\
\text { wound dressing, Nanofilm, Drug Delivery, Drug excipient. }\end{array}$ \\
\hline Laboratories & Protein immobilization, chromatographic techniques, tissue culture medium \\
\hline Electronics & Opto-electronics materials (liquid crystal displays) \\
\hline Energy & Membrane fuel cell (palladium) \\
\hline
\end{tabular}


BNC-based skin tissue repair materials was published by Chawla et al. (2009).

Besides improving the existing properties of BNC, composite materials have imparted BNC with new features displayed by typical inorganic or organic nanomaterials; these features include antibacterial effects; optical, electrical, and magnetic properties and catalytic and biomedical activities (Hu et al. 2014). For example, Shah et al. (2013) reviewed the applications of BNC composites in biomedical products, conducting materials, electrical devices, separation and waste purification, and composites with high mechanical strength for industrial applications. Additionally, Hu et al. (2014) reviewed the potential advantages and different applications of BNC-based functional nanomaterials, focusing mainly on application as sensors, photocatalytic nanomaterials, optoelectronic materials and devices, and magnetically responsive membranes.

The architecture of BNC materials can be engineered over length scales ranging from nano- to macro-sized by controlling the biofabrication process. Additionally, surface modifications have a vital role in determining the in vivo performance of biomaterials. Molina de Olyveira et al. (2013) studied the potential of gamma irradiation treatment for the modification of the surface properties of BNC, enhancing its potential for biomedical applications. Samples did not show significant variations in thermal properties; however, a higher pore density was produced in irradiated samples than in nonirradiated samples, resulting in slower diffusion than that observed in nonirradiated membranes.

$\mathrm{BNC}$ has a potential role in drug delivery systems. Müller et al. (2013) studied the applicability of BNC as a drug delivery system for proteins using serum albumin as a model drug. They found that freeze-dried samples showed lower uptake capacity for albumin than native BNC, which could be explained by changes in the fiber network during the freezedrying process. The integrity and biological activity of proteins could be retained during the loading and release processes. Rajwade et al. (2015) recently published a review of the applications of BNC in the biomedical field, such as scaffolds, carriers for drug delivery, and wound-dressing materials. Numata et al. (2015a) studied the combination BNC gel and amphiphilic block copolymer nanoparticles as a drug delivery system, and Cacicedo et al. (2015) created a hybrid microparticle system utilizing BNC and stereospecific nucleation of mesoporous hybrid microspheres composed of $\mathrm{CaCO}_{3}$. This hybrid system can be potentially used as an implantable drug delivery system for personalized oncological therapies.

Through enzymatic or acidic hydrolysis, BNC can form cellulose nanocrystals (NCCs), cellulose acicular particles with high crystallinity and with widths and lengths of 5$70 \mathrm{~nm}$ and between $100 \mathrm{~nm}$ and several micrometers, respectively (Klemm et al. 2011). NCCs also have many beneficial properties, including biocompatibility, biodegradability, and a lack of toxicity, making NCCs an excellent candidate for pharmaceutical applications. Owing to its negative change and large surface area, abundant amounts of drugs may be conjugated to the NCC surface. Furthermore, the hydroxyl groups on the surface of NCC can be modified with different functional groups, allowing the loading and release of drugs to be controlled (Akhlaghi et al. 2013).

According to Basmaji et al. (2014), the use of BNC as a part of the extracellular matrix is a novel biotechnology and unique medicine indicated for chronic wound treatment and management, drug delivery, tissue engineering, and skin cancer. Additionally, this material offers a tangible, effective solution to a serious medical and social problem, promoting rapid healing in lesions caused by diabetes, burns, ulcers of the lower limbs, or any other circumstances involving loss of epidermal or dermal tissue. In this context, novel antimicrobial peptides (AMPs) and bacterial cellulose/polyhexanide biguanide (PHMB), which are produced by symbioses culture between PHMB and green tea culture medium, result in a pure $3 \mathrm{D}$ structure consisting of an ultrafine network of novel matrix comprising biocellulose/PHMB nanofibers $(2-8 \mathrm{~nm})$ that is highly hydrated ( $99 \%$ in weight), has a high molecular weight, and exhibits good biocompatibility. Nimeskern et al. (2013) evaluated the potential applications of BNC as a graft material for replacement of ear cartilage. Moreover, Bäckdahl et al. (2011) evaluated the applications of BNC as vascular grafts.

\section{Future trends}

In 10 years, many attempts have been made to isolate strains that exhibit efficient production of cellulose, and many sources have been shown to enhance BNC production However, most studies have been performed using G. xylinus, and further analyses are needed to determine whether other bacterial strains may exhibit higher productivity. Additionally, studies on the cost-effectiveness of culture medium have provided improvements to BNC yield and productivity. Because BNC is a material of great industrial interest, with applications in a variety of fields, further efforts are necessary to make this biotechnological material a competitive product and economically viable. In brief, although several studies have investigated the applicability of BNC, many more studies are needed to explore the feasibility of biotechnological production, particularly the cost effectiveness of culture medium. Thereby, permitting more applications of BNC especially on nanotechnological area (i.e., nanoparticles for drug delivery, cosmetics, and food) and environmental (i.e., reduction of organic solvents or metals). 
Acknowledgments The authors received grants from the Coordination for Higher Level Graduate Improvements (CAPES/Brazil), National Council for Scientific and Technological Development (CNPq/Brazil), and State of São Paulo Research Foundation (FAPESP/Brazil, process numbers 2009/14897-7 and 2013/08617-7).

\section{Compliance with ethical standards}

Ethical statement/conflict of interest The authors, whose names appear on the submission, declare have contributed sufficiently to the scientific work and therefore share collective responsibility and accountability for the results. This manuscript has not been published or presented elsewhere in part or in entirety, and is not under consideration by another journal. There are no conflicts of interest to declare and this research not involved human participants or animals.

All the authors have approved the manuscript and agree with submission to your esteemed journal.

\section{References}

Akhlaghi SP, Berry RC, Tam KC (2013) Surface modification of cellulose nanocrystal with chitosan oligosaccharide for drug delivery applications. Cellulose 20:1747-1764. doi:10.1007/s10570-0139954-y

Almeida IF, Pereira T, Silva NHCS, Gomes FP, Silvestre AJD, Freire CSR, Sousa Lobo JM, Costa PC (2014) Bacterial cellulose membranes as drug delivery systems: an in vivo skin compatibility study. Eur J Pharm Biopharm 86:332-336. doi:10.1016/j.ejpb.2013.08. 008

Ashjaran A, Yazdanshenas ME, Rashidi A, Khajavi R, Rezaee A (2013) Overview of bio nanofabric from bacterial cellulose. J Text Inst 104: 121-131. doi:10.1080/00405000.2012.703796

Bäckdahl H, Risberg B, Gatenholm P (2011) Observations on bacterial cellulose tube formation for application as vascular graft. Mater Sci Eng C 31:14-21. doi:10.1016/j.msec.2010.07.010

Basmaji P, de Olyveira GM, dos Santos ML, Guastaldi AC (2014) Novel antimicrobial peptides bacterial cellulose obtained by symbioses culture between polyhexanide biguanide (PHMB) and green tea. J Biomater Tissue Eng 4:59-64. doi:10.1166/jbt.2014.1133

Basta AH, El-Saied H (2009) Performance of improved bacterial cellulose application in the production of functional paper. J Appl Microbiol 107:2098-2107. doi:10.1111/j.1365-2672.2009.04467.x

Cacicedo ML, Cesca K, Bosio VE, Porto LM, Castro GR (2015) Selfassembly of carrageenin-CaCO3 hybrid microparticles on bacterial cellulose films for doxorubicin sustained delivery. J Appl Biomed 13:239-248. doi:10.1016/j.jab.2015.03.004

Cai Z, Kim J (2009) Bacterial cellulose/poly(ethylene glycol) composite: characterization and first evaluation of biocompatibility. Cellulose 17:83-91. doi:10.1007/s10570-009-9362-5

Cakar F, Ozer I, Aytekin AÖ, Sahin F (2014) Improvement production of bacterial cellulose by semi-continuous process in molasses medium. Carbohydr Polym 106:7-13. doi:10.1016/j.carbpol.2014.01.103

Chawla PR, Bajaj IB, Survase SA, Singhal RS (2009) Microb Cellul : Fermentative Prod Appl 47:107-124

Conley K, Godbout L, Whitehead MA, Tony, Van De Ven TGM (2016) Origin of the twist of cellulosic materials. Carbohydr Polym 135: 285-299. doi:10.1016/j.carbpol.2015.08.029

Czaja W, Romanovicz D, Brown malcolm R (2004) Structural investigations of microbial cellulose produced in stationary and agitated culture. Cellulose 11:403-411. doi:10.1023/B:CELL.0000046412. 11983.61
Czaja WK, Young DJ, Kawecki M, Brown RM (2007) The future prospects of microbial cellulose in biomedical applications 8:1-12

de Azeredo HMC (2013) Antimicrobial nanostructures in food packaging. Trends Food Sci Technol 30:56-69. doi:10.1016/j.tifs.2012.11. 006

Donini I, De Salvi D, Fukumoto F, Lustri W, Barud H, Marchetto R, Messaddeq Y, Ribeiro S (2010) Biossíntese e recentes avanços na produção de celulose bacteriana. Eclética Química 35:165-178

Erbas Kiziltas E, Kiziltas A, Blumentritt M, Gardner DJ (2015a) Biosynthesis of bacterial cellulose in the presence of different nanoparticles to create novel hybrid materials. Carbohydr Polym 129: 148-155. doi:10.1016/j.carbpol.2015.04.039

Erbas Kiziltas E, Kiziltas A, Gardner DJ (2015b) Synthesis of bacterial cellulose using hot water extracted wood sugars. Carbohydr Polym 124:131-138. doi:10.1016/j.carbpol.2015.01.036

Fu L, Zhang J, Yang G (2013) Present status and applications of bacterial cellulose-based materials for skin tissue repair. Carbohydr Polym 92:1432-1442. doi:10.1016/j.carbpol.2012.10.071

Gomes FP, Silva NHCS, Trovatti E, Serafim LS, Duarte MF, Silvestre AJD, Neto CP, Freire CSR (2013) Production of bacterial cellulose by Gluconacetobacter sacchari using dry olive mill residue. Biomass Bioenergy 55:205-211. doi:10.1016/j.biombioe.2013.02. 004

Hu Y, Catchmark JM (2010) Influence of 1-methylcyclopropene (1$\mathrm{MCP}$ ) on the production of bacterial cellulose biosynthesized by Acetobacter xylinum under the agitated culture. Lett Appl Microbiol 51:109-113. doi:10.1111/j.1472-765X.2010.02866

Hu W, Chen S, Yang J, Li Z, Wang H (2014) Functionalized bacterial cellulose derivatives and nanocomposites. Carbohydr Polym 101: 1043-1060. doi:10.1016/j.carbpol.2013.09.102

Huang C, Guo H-J, Xiong L, Wang B, Shi S-L, Chen X-F, Lin X-Q, Wang C, Luo J, Chen X-D (2016) Using wastewater after lipid fermentation as substrate for bacterial cellulose production by Gluconacetobacter xylinus. Carbohydr Polym 136:198-202. doi: 10.1016/j.carbpol.2015.09.043

Jeon S, Yoo Y-M, Park J-W, Kim H-J, Hyun J (2014) Electrical conductivity and optical transparency of bacterial cellulose based composite by static and agitated methods. Curr Appl Phys 14:1621-1624. doi: 10.1016/j.cap.2014.07.010

Jozala AF, Aparecida R, Pértile N, Alves C (2015) Bacterial cellulose production by Gluconacetobacter xylinus by employing alternative culture media. Appl Microbiol Biotechnol 99(3):1181-1190. doi:10. 1007/s00253-014-6232-3

Jung H-I, Lee O-M, Jeong J-H, Jeon Y-D, Park K-H, Kim H-S, An W-G, Son H-J (2010) Production and characterization of cellulose by Acetobacter sp. V6 using a cost-effective molasses-corn steep liquor medium. Appl Biochem Biotechnol 162:486-497. doi:10.1007/ s12010-009-8759-9

Keshk S, Sameshima K (2006) Influence of lignosulfonate on crystal structure and productivity of bacterial cellulose in a static culture. Enzym Microb Technol 40:4-8. doi:10.1016/j.enzmictec.2006.07. 037

Keshk SM (2014) Bacterial cellulose production and its industrial applications. J Bioprocess Biotech 4:150. doi:10.4172/2155-9821. 1000150

Kim SS, Lee SY, Park KJ, Park SM, An HJ, Hyun JM, Choi YH (2015) Gluconacetobacter sp. gel_SEA623-2, bacterial cellulose producing bacterium isolated from citrus fruit juice. Saudi J Biol Sci. doi: 10.1016/j.sjbs.2015.09.031

Klemm D, Kramer F, Moritz S, Lindström T, Ankerfors M, Gray D, Dorris A (2011) Nanocelluloses: a new family of nature-based materials. Angew Chem Int Ed Engl 50:5438-5466. doi:10.1002/anie. 201001273

Kralisch D, Hessler N, Klemm D, Erdmann R, Schmidt W (2010) White biotechnology for cellulose manufacturing - the HoLiR concept. Biotechnol Bioeng 105:740-747. doi:10.1002/bit.22579 
Krystynowicz A, Czaja W, Wiktorowska-Jezierska A, GonçalvesMiśkiewicz M, Turkiewicz M, Bielecki S (2002) Factors affecting the yield and properties of bacterial cellulose. J Ind Microbiol Biotechnol 29:189-195. doi:10.1038/sj.jim.7000303

Kuo C-H, Chen J-H, Liou B-K, Lee C-K (2015) Utilization of acetate buffer to improve bacterial cellulose production by Gluconacetobacter xylinus. Food Hydrocoll 53:98-103. doi:10. 1016/j.foodhyd.2014.12.034

Kurosumi A, Sasaki C, Yamashita Y, Nakamura Y (2009) Utilization of various fruit juices as carbon source for production of bacterial cellulose by Acetobacter xylinum NBRC 13693. Carbohydr Polym 76: 333-335. doi:10.1016/j.carbpol.2008.11.009

Lee K-Y, Buldum G, Mantalaris A, Bismarck A (2014) More than meets the eye in bacterial cellulose: biosynthesis, bioprocessing, and applications in advanced fiber composites. Macromol Biosci 14:10 32. doi:10.1002/mabi.201300298

Li Z, Wang L, Hua J, Jia S, Zhang J, Liu H (2015) Production of nano bacterial cellulose from waste water of candied jujube-processing industry using Acetobacter xylinum. Carbohydr Polym 120:115119. doi:10.1016/j.carbpol.2014.11.061

Lin N, Dufresne A (2014) Nanocellulose in biomedicine: current status and future prospect. Eur Polym J 59:302-325. doi:10.1016/j. eurpolymj.2014.07.025

Lin D, Lopez-Sanchez P, Li R, Li Z (2014) Production of bacterial cellulose by Gluconacetobacter hansenii CGMCC 3917 using only waste beer yeast as nutrient source. Bioresour Technol 151:113119. doi:10.1016/j.biortech.2013.10.052

Lu Z, Zhang Y, Chi Y, Xu N, Yao W, Sun B (2011) Effects of alcohols on bacterial cellulose production by Acetobacter xylinum 186 . World $\mathrm{J}$ Microbiol Biotechnol 27:2281-2285. doi:10.1007/s11274-0110692-8

Lynd LR, Weimer PJ, van Zyl WH, Pretorius IS (2002) Microbial cellulose utilization: fundamentals and biotechnology. Microbiol Mol Biol Rev 66:506-577

Mautner A, Lee K-Y, Tammelin T, Mathew AP, Nedoma AJ, Li K, Bismarck A (2015) Cellulose nanopapers as tight aqueous ultrafiltration membranes. React Funct Polym 86:209-214. doi:10. 1016/j.reactfunctpolym.2014.09.014

Martínez-Sanz M, Lopez-Rubio A, Villano M, Oliveira CSS, Majone M, Reis M, Lagarón JM (2016) Production of bacterial nanobiocomposites of polyhydroxyalkanoates derived from waste and bacterial nanocellulose by the electrospinning enabling melt compounding method. J Appl Polym Sci 133. doi:10.1002/app. 42486

Mohammadkazemi F, Azin M, Ashori A (2015) Production of bacterial cellulose using different carbon sources and culture media. Carbohydr Polym 117:518-523. doi:10.1016/j.carbpol.2014.10.008

Molina de Olyveira G, Maria Manzine Costa L, Basmaji P (2013) Physically modified bacterial cellulose as alternative routes for transdermal drug delivery. J Biomater Tissue Eng 3:227-232. doi: 10.1166/jbt.2013.1079

Mikkelsen D, Flanagan BM, Dykes GA, Gidley MJ (2009) Influence of different carbon sources on bacterial cellulose production by Gluconacetobacter xylinus strain ATCC 53524. J Appl Microbiol 107:576-583. doi:10.1111/j.1365-2672.2009.04226.x

Müller A, Ni Z, Hessler N, Wesarg F, Müller FA, Kralisch D, Fischer D (2013) The biopolymer bacterial nanocellulose as drug delivery system: investigation of drug loading and release using the model protein albumin. J Pharm Sci 102:579-592. doi:10.1002/jps.23385

Nimeskern L, Martínez Ávila H, Sundberg J, Gatenholm P, Müller R, Stok KS (2013) Mechanical evaluation of bacterial nanocellulose as an implant material for ear cartilage replacement. J Mech Behav Biomed Mater 22:12-21. doi:10.1016/j.jmbbm.2013.03.005

Numata Y, Mazzarino L, Borsali R (2015a) A slow-release system of bacterial cellulose gel and nanoparticles for hydrophobic active ingredients. Int J Pharm 486:217-225. doi:10.1016/j.ijpharm.2015. 03.068

Numata Y, Sakata T, Furukawa H, Tajima K (2015b) Bacterial cellulose gels with high mechanical strength. Mater Sci Eng C Mater Biol Appl 47:57-62. doi:10.1016/j.msec.2014.11.026

Oliveira Barud HG, Barud Hda S, Cavicchioli M, do Amaral TS, de Oliveira Junior OB, Santos DM, Petersen AL, de OA, Celes F, Borges VM, de Oliveira CI, de Oliveira PF, Furtado RA, Tavares DC, SJL R (2015) Preparation and characterization of a bacterial cellulose/silk fibroin sponge scaffold for tissue regeneration. Carbohydr Polym 128:41-51. doi:10.1016/j.carbpol.2015.04.007

Padmanaban S, Balaji N, Muthukumaran C, Tamilarasan K (2015) Statistical optimization of process parameters for exopolysaccharide production by Aureobasidium pullulans using sweet potato based medium. Biotech 5:1067-1073. doi:10.1007/s13205-015-0308-3

Rajwade JM, Paknikar KM, Kumbhar JV (2015) Applications of bacterial cellulose and its composites in biomedicine. Appl Microbiol Biotechnol 99:2491-2511. doi:10.1007/s00253-015-6426-3

Rehim SA, Singhal M, Chung KC (2014) Dermal skin substitutes for upper limb reconstruction. Hand Clin 30:239-252. doi:10.1016/j. hcl.2014.02.001

Ruka DR, Simon GP, Dean KM (2012) Altering the growth conditions of Gluconacetobacter xylinus to maximize the yield of bacterial cellulose. Carbohydr Polym 89:613-622. doi:10.1016/j.carbpol.2012.03. 059

Santos-Ebinuma VC, Roberto IC, Simas Teixeira MF, Pessoa A (2013) Improving of red colorants production by a new Penicillium purpurogenum strain in submerged culture and the effect of different parameters in their stability. Biotechnol Prog 29:778-785. doi:10. 1002/btpr.1720

Schramm M, Hestrin S (1954) Factors affecting production of cellulose at the air/liquid interface of a culture of Acetobacter xylinum. J Gen Microbiol 11:123-129. doi:10.1099/00221287-11-1-123

Shah N, Ul-Islam M, Khattak WA, Park JK (2013) Overview of bacterial cellulose composites: a multipurpose advanced material. Carbohydr Polym 98:1585-1598. doi:10.1016/j.carbpol.2013.08.018

Shi Z, Zhang Y, Phillips GO, Yang G (2014) Utilization of bacterial cellulose in food. Food Hydrocoll 35:539-545. doi:10.1016/j. foodhyd.2013.07.012

Tanskul S, Amornthatree K, Jaturonlak N (2013) A new celluloseproducing bacterium, Rhodococcus $s p$. MI 2: screening and optimization of culture conditions. Carbohydr Polym 92:421-428. doi:10. 1016/j.carbpol.2012.09.017

Thompson DN, Hamilton MA (2001) Production of bacterial cellulose from alternate feedstocks. Appl Biochem Biotechnol 91-93:503514. doi:10.1385/ABAB:91-93:1-9:503

Trovatti E, Serafim LS, Freire CSR, Silvestre AJD, Neto CP (2011) Gluconacetobacter sacchari: an efficient bacterial cellulose cell-factory. Carbohydr Polym 86:1417-1420. doi:10.1016/j.carbpol.2011. 06.046

Tyagi N, Suresh S (2015) Production of cellulose from sugarcane molasses using Gluconacetobacter intermedius SNT-1: optimization \& characterization. J Clean Prod. doi:10.1016/j.jclepro.2015.07.054

Wu J-M, Liu R-H (2012) Thin stillage supplementation greatly enhances bacterial cellulose production by Gluconacetobacter xylinus. Carbohydr Polym 90:116-121. doi:10.1016/j.carbpol.2012.05.003

Wu S-C, Li M-H (2015) Production of bacterial cellulose membranes in a modified airlift bioreactor by Gluconacetobacter xylinus. J Biosc Bioeng 120(4):444-449. doi:10.1016/j.jbiosc.2015.02.018

Zhang S, Winestrand S, Guo X, Chen L, Hong F, Jönsson LJ (2014) Effects of aromatic compounds on the production of bacterial nanocellulose by Gluconacetobacter xylinus. Microb Cell Factories 13:62. doi:10.1186/1475-2859-13-62 